\title{
La reconquista del paisaje arquitectónico: los pueblos adoptados en Asturias
}

\author{
The reconquest of the architectural landscape: \\ the adopted villages in Asturias
}

\author{
Miriam ANDRÉS EGUIBURU \\ Universidad de Oviedo
}

Recibido: 14-IV-2015 / Aceptado: 15-VII-2015

Resumen: La Dirección General de Regiones Devastadas fue el organismo encargado tanto de llevar a cabo como ejercer un férreo control sobre la reconstrucción arquitectónica del país en la inmediata posguerra (1938-1957).

Además de la tarea puramente material, el componente ideológico y propagandístico fue muy relevante en sus acciones, siendo especialmente notable tras la aprobación del Decreto de Adopción de Pueblos Adoptados, según el cual el Estado asumía la total reconstrucción de aquellas localidades que hubieran sido gravemente dañadas por la guerra.

En el caso asturiano fueron siete los pueblos adoptados, en los que se materializaron todos los principios teóricos y prácticos del organismo, y que modificaron para siempre su paisaje arquitectónico.

Palabras clave: Dirección General de Regiones Devastadas, Reconstrucción, Guerra Civil, Pueblos adoptados, Asturias.

ABSTRACT: The General Direction of Devastated Regions was the body entrusted with, not only perform the reconstruction of the country, but also to exercise full control over it in the period immediately after the Civil War (1938-1957).

In addition to the task purely material, ideological and propaganda component was very relevant in their actions, being especially notable after the approval of its Decree of adoption, whereby the state assumed complete reconstruction of those localities which have been severely damaged by war.

In the Asturian case seven villages were adopted, in which all theoretical and practical principles of the organism were materialized, and this changed its architectonical landscape forever.

Keys words: General Direction of Devastated Regions, Reconstruction, Civil War, Adopted villages, Asturias.

La fraticida Guerra Civil Española dejó tras de sí un desolador paisaje de dolor y destrucción, afectando a todos los niveles de la vida cotidiana de sus habitantes ${ }^{1}$. Entre

${ }^{1}$ El presente trabajo se ha realizado al amparo de una beca de Formación de Personal Investigador, en el los retos a los que debía enfrentarse el nue-

marco del proyecto de investigación "Restauración y reconstrucción monumental en España 1938-1958. Las Direcciones Generales de Bellas Artes y de Regiones Devastadas", ref. HUM2007-62699, financiado por el Ministerio de Ciencia y Tecnología, Dirección General 
vo poder emergente se encontraba el objeto de este estudio: la reconstrucción arquitectónica de un país absolutamente mutilado. A este propósito se unirían otros tantos, de diferente naturaleza, que acompañarían a esta labor primeramente material, contribuyendo a la consolidación ideológica de un Régimen ilegítimo.

\section{LA DIRECCIÓN GENERAL DE RE- GIONES DEVASTADAS: UN NUEVO ORGANISMO PARA UN NUEVO ES- TADO}

A medida que la guerra avanzaba, los futuros vencedores iban adquiriendo nuevas provincias y, con ello, nuevas ruinas ${ }^{2}$. Como consecuencia de esta larga contienda, y a la manera de otros países europeos que trataron de recuperarse de episodios bélicos de gran magnitud ${ }^{3}$, en sus primeras disposiciones el gobierno nacional contemplaba la creación de un Servicio destinado a la tarea de su reconstrucción arquitectónica.

El territorio asturiano fue pionero en esta implantación, contando con un reseñable antecedente, aún dolorosamente cercano: el Patronato para la reconstrucción de la Cámara $\mathrm{Santa}^{4}$, formado tras la traumática voladura de la misma en Octubre de 1934. Es precisamente en esta región en la que

de Programas y Transferencia de Conocimiento, Subdirección General de Proyectos de Investigación.

\footnotetext{
2 "La recuperación de la totalidad del territorio nacional nos ponía en posesión de nuevas provincias, pero también de nuevas ruinas...". Discurso del Ministro de la Gobernación Serrano Suñer en "Número extraordinario dedicado a la Exposición de la Reconstrucción de España", Reconstrucción, n 3, 1940, p. 2.

${ }^{3}$ M. BLANCO LAGE, "La arquitectura en Regiones Devastadas", $A V$, no 3, 1985, p. 38. Son tomados como modelos estados como Italia, Francia o Bélgica, que tuvieron que enfrentarse a los desastres de la I Guerra Mundial, adoptando incluso el nombre del organismo de esta última Service des Régions Devastées.

${ }^{4}$ García Cuetos desarrolla ampliamente este tema en J. ESTEBAN CHAPAPRÍA y M. P. GARCÍA CUETOS, Alejandro Ferrant y la conservación monumental en España (1929-1939). Castilla y León y la primera zona monumental, Salamanca, 2007, vol. II, pp. 138 y ss.
}

se creó, de manera pionera, por Orden del 7 de diciembre de 1937, la Comisión Informadora de la Reconstrucción de Oviedo, pocos meses después del fin de la guerra en el frente Norte ${ }^{5}$. Los motivos que justifican su implantación, tal como figuran en el primer párrafo de dicha Orden, ya adelantan el posterior uso ideológico que daría el Régimen a las numerosas ruinas que salpicaban el paisaje español ${ }^{6}$.

A través del ensalzamiento de aquellos que "lucharon por España", se reafirmaba el gobierno nacional como reconstructor de la destrucción que los republicanos habían provocado. Este discurso de "gesta heroica" fue posteriormente una constante en las tareas de reconstrucción, incorporándose a la literatura de la época y a los discursos del Caudillo.

El hecho de que esta comisión fuera creada en Oviedo respondía a diferentes motivos: la destrucción provocada por el constante asedio a la capital (aún con marcas tangibles de Octubre del 34), el tratarse de un frente ya establecido, y la tremenda carestía de viviendas ${ }^{7}$. Sin embargo, la necesidad de la creación de un organismo de similares características, pero de ámbito nacional, se hizo cada vez más urgente, tenien-

${ }^{5}$ La Comisión Informadora de la Reconstrucción de Oviedo es ya reseñada por: J. M. LÓPEZ GÓMEZ, Un modelo de arquitectura y urbanismo franquista en Aragón: la Dirección General de Regiones Devastadas 1939-1957, Zaragoza, 1995, p. 27 y E. LLANOS DE LA PLAZA, “La Dirección General de Regiones Devastadas: su organización administrativa", Arquitectura en Regiones Devastadas, Madrid, 1987, pp. 41-50.

${ }^{6}$ BOE, 8 de diciembre de 1937. "El nombre de Oviedo, incorporado para siempre a la historia de España, está en trance de dejar de representar a una ciudad viva para convertirse en la pura designación de un acontecimiento histórico: que sobre lo que fue solar de la capital de Asturias ya no quedan sino escasos edificios en medio de inmensas ruinas narradoras dramáticas del heroísmo fecundamente gastado".

7 S. TOMÉ FERNÁNDEZ, La formación de la ciudad burguesa 1850-1950, Oviedo, 1988, p. 215. Señala que la estimación oficial de la catástrofe arrojaría un balance de tres mil edificios siniestrados, perdiéndose un $75 \%$ de su capacidad de alojamiento. 
do en cuenta la duración y la intensidad que estaba caracterizando la contienda.

Por este motivo, el 30 de enero de 1938 fue creado el Servicio de Regiones Devastadas y Reparaciones, suscrito al Ministerio del Interior. El Decreto del 25 de marzo de 1938 determinó sus bases, en las que se establecía no solo que el Estado tomaba las riendas de la reconstrucción del país, sino que creaba de esta manera un Servicio que realizaría el total control de la misma ${ }^{8}$, a través de siete comisiones de reconstrucción distribuidas en las zonas de mayor destrucción del país9. La Zona Cantábrica, que es la que nos ocupa, estaría formada por las provincias de Oviedo, Santander, León y Palencia ${ }^{10}$.

El 8 de agosto de 1939 el Servicio de Regiones Devastadas y Reparaciones se convirtió en la Dirección General de Regiones Devastadas, aprobando el 23 de Septiembre de 1939 el Decreto de Adopción de Pueblos Adoptados. Siguiendo el modelo belga, en concreto la ley de 1919 del Services des Régions Devastées, el Jefe del Estado adoptó aquellas poblaciones en las que la destrucción había "afectado a casi la totalidad de los bienes de uso público y de los destinados a servicios en la localidad"11.

La evolución de los bienes objeto de protección al amparo de la citada ley fue constante, dejando incluso de ser requisito indispensable que los daños se debieran a la contienda en sus últimos años ${ }^{12}$. A la vista de este desarrollo, podríamos concluir que la tarea de la que se ocupaba inicialmente el organismo fue culminada de manera inminente $y$, como consecuencia, se incluyeron nuevos objetivos. La realidad no puede más que desmentir este supuesto, ya que, avanzada la década de los 40, la mayor parte de las intervenciones se encontraban, en el mejor de los

\footnotetext{
${ }^{8}$ BOE, 29 de marzo de 1938.

${ }^{9} \mathrm{BOE}, 15$ de junio de 1938 .

${ }^{10} \mathrm{BOE}, 17$ de junio de 1938.

${ }^{11}$ BOE, 1 de octubre de 1939, pp. 5489-5490.

${ }^{12}$ BOE, 15 de diciembre de 1950, pp. 5843-5844.
}

casos, en pleno proceso constructivo, como se ejemplificará a continuación. Entendemos que estas nuevas funciones responden al objetivo propagandístico que protagonizó la tarea del organismo, a través de la intervención de la Dirección en catástrofes, como las inundaciones en Cataluña o la adopción de comarcas deprimidas económicamente como el caso de Las Hurdes ${ }^{13}$, mostraban un gobierno capaz de hacer frente a sus problemas reales, de reafirmación del Caudillo de la Reconstrucción.

Este concepto, que ya venía señalado en el primero de los números de la revista Reconstrucción ${ }^{14}$, se incluía en la nueva triple condición que encarnaba en su persona el propio Francisco Franco, a saber: Generalísimo, Jefe de Estado y Caudillo de la Reconstrucción. Resulta especialmente significativa la importancia de la que se dotaba a esta atribución, equiparada al hecho de haber sido (y de continuar siendo) general del ejército que permitió la liberación de España y de haberse alzado como cabeza del Estado. Consideramos, por lo tanto, que la intencionalidad tendría un doble sentido: en primer lugar justificar los dos cargos anteriores -era necesaria una guerra y es necesaria la presencia de un Caudillo que redirija el destino perdido de España hacia su reconstrucción (material y moral)- y, en segundo lugar, la ya reiterativa necesidad de consolidar ese Régimen fuerte: Franco es el Generalísimo, es el Jefe del Estado y reconstruirá un país mutilado por el anterior gobierno.

En el caso asturiano, este título de Caudillo de la Reconstrucción adquiere una connotación especial al contar entre los períodos más florecientes de nuestro pasado con otro Caudillo de gran relevancia, tam-

\footnotetext{
${ }^{13}$ Según señala J. M. LÓPEZ GÓMEZ, Op. cit., p. 37. La intervención efectiva de la Dirección en estos casos aún no ha sido constatada.

${ }^{14}$ Reconstrucción, n. ${ }^{\circ} 1,1940$, p. 2 . En ella se denomina a Franco como "Excmo. Sr. D. Francisco Franco Bahamonte, Generalísimo de los Ejércitos de España, Jefe del Estado, Caudillo de la Reconstrucción Nacional".
} 
bién reconstructor, pero de la España Católica: el rey Pelayo, Caudillo de la Reconquista.

La Dirección General de Regiones Devastadas se extinguió definitivamente en el año 1957, cuando la función para la que fue creada, la Reconstrucción Nacional, se consideró finalizada. En este año fue creado el Instituto de la Vivienda, en el que se integró la Dirección General de Arquitectura, Economía y Técnica de la Construcción que asumió, entre otras, sus competencias.

\section{LOS PUEBLOS ADOPTADOS EN AS- TURIAS}

A partir del Decreto de octubre de 1939, la mayor parte de las intervenciones de la Dirección General de Regiones Devastadas se centraron en la reconstrucción de los pueblos adoptados.

Esta adopción suponía, en teoría, para una localidad que: los técnicos del Estado redactarían un plan nuevo o de mejora de su urbanismo, el Estado restablecería los servicios públicos, construiría viviendas de renta reducida, se reservaría el derecho a expropiaciones para sus propósitos de mejora y dispondría la conservación de las ruinas que considerara $^{15}$.

En lo que respecta a las expropiaciones, se le confiere a la Dirección General de Regiones Devastadas la facultad de "expropiar terrenos, solares, bienes y derechos de toda clase", "obviando plazos y actuaciones" y, de acuerdo a sus intereses, se podía "obligar a los receptores de indemnizaciones por expropiación a que el importe de la misma se invierta en la reconstrucción"16. Por ello, las expropiaciones forzosas fueron una de las cuestiones más controvertidas en la tarea reconstructora de la Dirección General de Regiones Devastadas. Además del descontento por parte de los propietarios, que ejemplificaremos en el caso del pueblo asturiano de Tarna, los procedimientos legales

\footnotetext{
${ }^{15}$ BOE, 1 de octubre de 1939.

${ }^{16}$ Ibídem.
}

que acarreaban dificultaron en ocasiones las actuaciones del organismo.

En lo tocante a la conservación de ruinas, en la provincia asturiana hemos podido constatar una intervención temporal en el "glorioso" cuartel de Simancas en Gijón, que se mantuvo por un período de tiempo en estado de ruina con un fin ejemplificante y de esta manera fue reproducido en una maqueta para perpetuarlo en el tiempo ${ }^{17}$.

Tras este trasfondo teórico, hemos constatado varios objetivos -además del puramente material-, que también pretendían alcanzarse con esta reconstrucción. En primer lugar encontramos el incuestionable trasfondo propagandístico de la reconstrucción llevada a cabo por el organismo. La reiterada contraposición que se trató de establecer entre el republicano destructor y el nacional reconstructor, cobró una trascendental importancia en el caso de los "pueblos adoptados", a través de los que se trataba de dejar patente el estado de abandono en el que el gobierno republicano había permitido que se estancaran dichas localidades. Los hechos que se denunciaban eran, en la mayoría de los casos, absolutamente reales, si bien es el contexto en el que se inscriben -la dicotomía entre el Estado durante el "dominio rojo" y la reconstrucción realizada por los nacionales-, el que determina el componente propagandístico que se evidencia en estas afirmaciones.

En este sentido, nos gustaría reseñar los lazos que trataron de establecerse entre este período y el glorioso pasado nacional, evidenciadas en este discurso de Serrano Suñer, en el que con su comparación de los pueblos adoptados adelanta la puesta en marcha de todo un aparato propagandístico que, como veremos, trataron también de trasladar al terreno arquitectónico.

${ }^{17}$ M. ANDRÉS EGUIBURU, La reconstrucción de Gijón: la labor de la Dirección General de Regiones Devastadas en Gijón, Gijón, 2012, pp. 68-87 e ÍDEM, “La arquitectura de la Victoria: el cuartel de los héroes de Simancas en Gijón", en Actas de IV Congreso de Investigadores sobre el Franquismo, Santiago de Compostela, 2011, pp. 444-454. 
"Son mandatos de fundación que recuerdan las cartas pueblas de nuestra Edad Media y las gestas heroicas de nuestro conquistadores de Indias"18.

Como medio difusor de todos estos propósitos encontramos la revista Reconstrucción, órgano propagandístico de la Dirección General de Regiones Devastadas, que dedicó diez artículos monográficos a "pueblos adoptados" en los que se plasmaban estas premisas. Además, en ella se presentan hechos tan manipulados como la atribución del incendio de Guernica a los republica$\operatorname{nos}^{19}$. Muchas de las intervenciones de las que se hacía eco la propaganda de la Dirección General de Regiones Devastadas -a través de exposiciones, publicaciones y maquetas-, no llegaban jamás a materializarse, tal sería el caso de Santander, adoptada tras el incendio que la asoló en febrero de 1941, en la que solo se actuó finalmente sobre su catedral $^{20}$.

Por otra parte, se pretendía ideologizar esta reconstrucción, hacer patentes arquitectónicamente los ideales del Régimen. En este sentido, se dotaba al arquitecto de una labor casi misional, no solo se debía reconstruir, sino que también se debía fomentar con las nuevas arquitecturas un cambio en las costumbres, siempre en un contexto de doble reconstrucción: material y moral. Un buen ejemplo de ello fue la creación de "buenos hogares": no era suficiente crear viviendas, sino que en ellas debía desarrollarse una vida conforme a los valores del Nuevo Régimen, en consonancia con la doble reconstrucción señalada. A este respecto, resultan muy ilustrativas las palabras de José Moreno Torres, director de la Dirección General de Regiones Devastadas:

\footnotetext{
${ }^{18}$ Discurso pronunciado por Serrano Suñer en $O p$. cit., p. 2.

${ }^{19}$ G. CÁRDENAS, “Estudio de un pueblo adoptado: Guernica", Reconstrucción, no 1, 1940, p. 22.
}

${ }^{20} \mathrm{R}$. RODRÍGUEZ LLERA, La reconstrucción urbana de Santander 1941-1950, Santander, 1980, p. 42.
"Lo primero que hay que reconstruir es la idiosincrasia. No basta con devolver hogares y sanear los medios rurales de España. Es necesario que cambien las costumbres" ${ }^{21}$.

Este concepto de los "buenos hogares" estaba, además, muy ligado al nuevo nacionalcatolicismo. Se pretendía que en estas nuevas viviendas se pudiera desarrollar una vida conforme a los valores católicos que se basaban, entre otros, en una absoluta separación de los espacios entre hombres y animales, así como entre sexos, que impidiera tanto la promiscuidad como la precocidad sexual $^{22}$.

Todas estas premisas las recogemos en el caso asturiano. Las circunstancias que determinan las diferencias de estas localidades frente a otras del territorio nacional son: algunas de sus dificultades de reconstrucción, el desarrollo de la guerra en Asturias y los criterios de intervención aplicados a cada uno de los lugares.

En el primero de los decretos de adopción ya encontramos, junto a localidades tan emblemáticas como Brunete, Belchite o Potes, algunos de los "pueblos adoptados" en Asturias: Tarna, Pendones, Las Regueras y Oviedo $^{23}$. A ellos habría que añadir, en sucesivas adopciones, los pueblos de Nava, Campo de Caso y Cangas de Onís. Cada uno de ellos contaba con una oficina comarcal y su situación en el mapa refleja las campañas más duras de la Guerra Civil. Ideológicamente, pronto se establecieron lazos entre la Reconquista española y la gesta que los nacionales estaban desarrollando en tierras asturianas ${ }^{24}$.

${ }^{21}$ J. MORENO TORRES, “Un organismo para un nuevo estado", Reconstrucción, no 12, 1941, p. 9.

${ }^{22}$ L. PRIETO BANCES, "El proyecto y buen uso de la vivienda", Reconstrucción, n.. 17, 1941, pp. 21-32. "La casa hemos de concebirla, con el sentido tradicional del hogar español, como primer centro de educación cristiana y familiar...".

${ }^{23}$ BOE, 22 de octubre de 1939, p. 5916.

${ }^{24}$ Discurso de Franco en Gijón, Septiembre de 1939, recogido en: D. RUIZ (coord.), Asturias contemporánea. 
Esta compleja tarea reconstructiva no estuvo exenta de problemas y dificultades en el momento de su materialización ${ }^{25}$. Al más común, de tipo económico, se suman otros como la difícil la tarea de reclusión de personal y del transporte del mismo, así como de materiales. El exilio, depuración o muerte de un número importante de arquitectos, se unía a la dificultad de que estos facultativos accedieran a trasladar su domicilio a los pueblos objeto de reconstrucción, tal como exigía la Dirección General de Regiones Devastadas. Estas circunstancias se hicieron aún más complicadas en nuestra región, tanto por la calidad de alta montaña de algunas de las localidades adoptadas, como por la inexistencia de efectivos suficientes para mano de obra en los propios pueblos, por lo que forzosamente había que trasladarlos desde la capital o localidades cercanas cada día ${ }^{26}$.

Debemos señalar que estos dos aspectos, la carestía de medios económicos y de profesionales cualificados, determinaron en gran medida el destino de muchos de los edificios objeto de reconstrucción, dando lugar a intervenciones de muy variada calidad. Este punto era común a algunos de los países europeos que trataban de recuperarse de la Segunda Guerra Mundial, encontrando importantes paralelismos con el caso italia$\mathrm{no}^{27}$.

1808-1975. Síntesis histórica. Textos y documentos, Madrid, 1981, p. 139. "Yo sabía que fracasarían, porque tenía fe en los asturianos, en el temple de los que aquí se defendían y, ¿por qué no decirlo? confianza en Dios. Si un día el milagro de la fe y el portento divino puso en manos de los asturianos la Cruz de la Victoria; si ésta fue cuna de la Reconquista, ¿cómo podría dejar Dios que pereciese lo que antes había salvado el tesoro de la fe española?".

${ }^{25}$ Algunos de estos problemas son citados por $\mathrm{J}$. MORENO TORRES, Op.cit., pp. 9-13.

${ }^{26}$ Archivo General de la Administración (en adelante AGA). Expediente 76/04/1191. Informe sobre solución personal Tarna. En él se barajan todas las posibilidades de traslado y alojamiento de los trabajadores a fin de encontrar una solución lo más económica posible.

${ }^{27} \mathrm{~A}$. BARBACCI, Il restauro dei monumenti in Italia, Milán, 1956, p. 10. “Quest'opera, come quella volta al restauro ordinario, non sempre soddisfa pienamente
En este mismo sentido, el clima y la orografía de estos pueblos aportaría más inconvenientes a la tarea: por ejemplo, en el concejo de Caso -en el que se localizan tres de estos pueblos- se elevan numerosas cumbres de aproximadamente 2.000 metros, encontrándose el $39 \%$ de su superficie a más de 1.200 metros.

A todo esto, debemos añadir la obligación de realizar las obras por administración directa, ya que las subastas se quedaban desiertas ${ }^{28}$. En cuanto a los materiales, se extraían de canteras castellanas, por encontrarse más próximas que las asturianas, fundamentalmente se trataba de: Lillo, a 16 km., Cuevas de Armada, a 21 km., y Boñar, a $80 \mathrm{~km}^{29}$.

per quantità e qualità. Ciò deriva da varie cause; in primo luogo perché l'Italia, se è rica di memorie, non lo è altrettanto di mezzi economici... Inoltre, perché l'opera restauratrice non è racionalmente organizzata; in particolar modo quella riguardante la riparazione dei dan di guerra, troppo spesso affidata a tecnici sprovvisti della necesaria preparazione". La traducción literal de esta cita sería: "Esta obra, como aquella de la restauración ordinaria, no siempre satisface en cantidad y calidad. Esto deriva de varias causas; en primer lugar porque Italia, si es rica de memoria, no lo es tanto de medios económicos (...). Además, porque la obra de restauración no está racionalmente organizada; en particular manera la que abarca la reparación de daños de guerra, habitualmente confiada a técnicos desprovistos de la preparación necesaria".

${ }^{28}$ Encontramos repetida esta circunstancia en cada una de las intervenciones llevadas a cabo en el concejo.

${ }^{29}$ AGA. Expediente 76/13/20494. Informe sobre transporte de materiales. "Para cada 2 metros cúbicos de arena a poner a pie de obra en Tarna, desde la gravera denominada "La Requejada" ha sido necesario pasar de la cota de 906 metros del pueblo a la 1.625 del Alto de la Raya, en cuyo punto, parte un ramal de unos $500 \mathrm{~m}$ de longitud al arenero, es decir, que ha habido que subir al Puerto de Tarna para alcanzar la divisoria de la cordillera Astur-leonesa y, una vez alcanzada esta, remontar el puerto del Alto de la Raya, para alcanzar a su vez la divisoria de los valles del río Porma y del río Esla, en la carretera que va desde el puerto de Tarna a Boñar. Esto de por sí significa ya una labor ardua, si se tiene en cuenta que el número de metros cúbicos transportados de este material se elevó a cerca de los 1.500 en el periodo comprendido entre mediados de mayo a últimos de noviembre". 
Otro de los problemas fundamentales, común a muchos de los pueblos reconstruidos, no solo en el caso español, sino también en ejemplos similares en la vecina Italia, fue el mal estado en el que se encontraban con anterioridad a los daños bélicos ${ }^{30}$. A este respecto, podemos señalar cómo el pueblo de Tarna no contaba con los servicios más básicos, como alcantarillado ni agua corriente, sino que los tarninos y su ganado se abastecían de un manantial situado en la parte alta del pueblo, por lo que el organismo tuvo que captarlo, almacenarlo y conducirlo, para su mejor aprovechamiento. Las calles tampoco contaban con aceras ni pavimento $y$, tal como señala el informe, "la calzada en días de lluvia se convierte en un lodazal instransitable" ${ }^{\prime 31}$. En cuanto a la luz eléctrica, era defectuosa y precaria, por lo que debió instalarse un tercer hilo con transformador que permitiera el acceso a la luz para las viviendas y las obras ${ }^{32}$. En otros casos, para acometer las obras era necesario construir primero las carreteras, como ocurriría en la ermita del Cristo las Cadenas de la capital asturiana, a la que el acceso resultaba imposible tras las destrucciones debidas a la guerra en sus inmediaciones ${ }^{33}$.

La última de las dificultades que vamos a señalar se encuentra en clara relación con uno de los objetivos que se perseguían en la reconstrucción de estos pueblos: el fuerte componente propagandístico. Tal como señalaba Ascensión Hernández para el caso de Teruel, tras el decreto de adopción, tuvo lugar un "énfasis constructivo", que, en lo concerniente al territorio que nos ocupa,

${ }^{30}$ L. SERAFINI, "Ricostruzione in Abruzzo nel secondo dopoguerra", Restaurando la memoria. España e Italia ante la recuperación monumental de posguerra, Gijón, 2010, pp. 241-244.

${ }^{31}$ AGA. Expediente 76/04/1191. Plan de urbanización de Tarna. Francisco de Saro.

32 AGA. Expediente 76/13/20494. Informe y presupuesto instalación transformador eléctrico Tarna.

33 AGA. Expediente 76/04/1323 y 76/13/20503. Proyecto de reconstrucción de la Ermita del Cristo de las Cadenas. Juan Antonio Miralles Sastre. fue muy inapropiado ${ }^{34}$. Retomando las primeras pinceladas de la reconstrucción de la localidad de Tarna, fue la voluntad de que protagonizara el nuevo paisaje asturiano en exposiciones, en la citada revista Reconstrucción $\mathrm{y}$, sobre todo, en un conjunto de postales en las que junto a otros ejemplos se hacían eco de la importante obra realizada por el Nuevo Régimen en la región ${ }^{35}$, la que precipitó unas primeras intervenciones rápidas y de escasa calidad que culminaron con el derrumbamiento de algunas de las cubiertas de las nuevas viviendas construidas ${ }^{36}$.

En cuanto a los criterios aplicados para materializar esta reconstrucción hemos establecido, a grandes rasgos, dos maneras muy generales de enfrentarse a la intervención: reconstrucción material y reconstrucción propagandística.

Partiendo de la base de que todas las intervenciones tienen un componente principal que es el material, queremos englobar con este término a las intervenciones que tuvieron este objetivo como protagonista, es decir, que a partir de esta inversión se pretendía fundamentalmente reactivar la actividad económica del pueblo. Podría decirse que se trata de una "reconstrucción a cambio de producción". Podemos encuadrar en esta "reconstrucción material", sin descartar en ningún caso el componente propagandístico -muy potente especialmente en el aparato que acompañó en los primeros años el caso de Tarna, aunque no en los estilos o tipolo-

${ }^{34}$ A. HERNÁNDEZ “Arquitectura, restauración y liturgia. Manuel Lorente Junquera y las catedrales aragonesas", Historia, restauración y reconstrucción monumental en la posguerra española, Madrid, 2012, pp. 97-132.

${ }^{35}$ En este conjunto de postales no solo se utilizaba el material gráfico como propaganda de las intervenciones, sino que se acompañaban de pequeños textos que rezaban: "Así quedó Tarna, pero el Caudillo le ha devuelto la vida con suprema belleza" o "estos montones de piedra fueron la Tarna destruida por los rojos y reconstruida ya por la España imperial", entre otras.

${ }^{36}$ Los vecinos presentaron esta queja, entre otras, en una misiva que dirigen al Caudillo, recogida en G. MARTÍNEZ TESTÓN, Memoria histórica de Tarna: "coses nuestres", Oviedo, 2004, pp. 443-446. 
gías seleccionados para la reconstrucción de sus edificios- los siguientes pueblos: Tarna, Pendones, Las Regueras (los tres adoptados en el primero de los decretos del 7 de Octubre de 1937, junto a Oviedo ${ }^{37}$ ) y la Foz (no se trata estrictamente de un "pueblo adoptado", pero su tratamiento y circunstancias han determinado que lo consideremos como uno de ellos). La intervención más interesante sería la llevada a cabo en la localidad de Tarna, por lo que nos centraremos en ella como la más representativa de esta naturaleza.

Del mismo modo que el componente material está presente en todas las intervenciones, también lo está el propagandístico. Englobamos con este término a las tareas llevadas a cabo en determinadas localidades, atendiendo únicamente a sus edificios representativos -tales como la iglesia principal, el ayuntamiento, la plaza mayor o el cuartel-, relegando otras importantes carencias como la carestía de viviendas a un segundo plano. Con ello, la Dirección General de Regiones Devastadas obtenía, a cambio de una pequeña inversión una gran presencia en los pueblos objeto de la misma (y por extensión del nuevo Régimen), mostraba su poder y justificaba las penurias atravesadas a cambio de una mejora en el país. Engrosarían esta lista las capitales de concejo Nava, Cangas de Onís (incluyendo el amplio aparato propagandístico que rodearía la reconstrucción de Covadonga), Campo de Caso y, por supuesto, Oviedo.

Pese a que las intervenciones propagandísticas de mayor envergadura tuvieron lugar en la capital, Oviedo, y en el crucial enclave de Covadonga, hemos creído que la localidad de Nava ejemplifica de mejor manera la contraposición a la reconstrucción material, por no contar con unas connotaciones ideológicas tan evidentes.

\footnotetext{
${ }^{37}$ BOE, 22 de octubre de 1939, p. 5916.
}

\section{TARNA: RECONSTRUCCIÓN A CAM- BIO DE PRODUCCIÓN}

El estado de la localidad de Tarna tras la contienda era tan desolador que la más apremiante de sus necesidades pasaba por habilitar viviendas que dieran a sus habitantes la posibilidad de continuar su vida cotidiana, tratando de evitar una emigración forzosa ${ }^{38}$.

Su adopción se realizó tras una visita personal que el Caudillo realizó al pueblo, en la que contemplando sus ruinas manifestó su intención de que fuera uno de los primeros pueblos reconstruidos en España ${ }^{39}$.

La evaluación de su destrucción se estimó, según datos de la revista Reconstrucción, en 400.000 pesetas $^{40}$. Su magnitud fue tal que afectó a la mayor parte de la extensión del solar, librándose únicamente la fábrica de la iglesia, las casas construidas en la ladera y las escuelas que coronan el pueblo (Fig. 1).

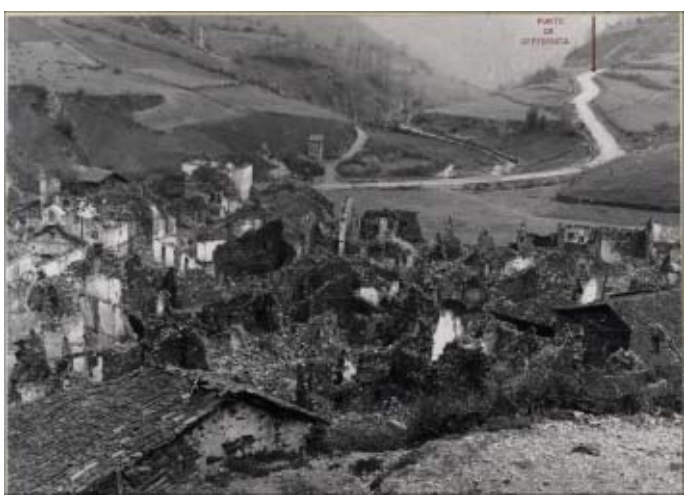

- Fig. 1. Estado del pueblo de Tarna tras el incendio de 1936. AGA, caja F-04228-027-004.

${ }^{38}$ M. BEASCOA, "Reconstrucción de Asturias", Reconstrucción, no 2, 1940, p. 7. “(...) Si bien ha adquirido caracteres de generalidad, tanto en la capital como en el resto de la región, la destrucción de los edificios públicos y religiosos, el problema verdadero, por su premura, lo constituye la calificación destinada a viviendas, ya que existen pueblos como Tarna, Pendones, La Foz, Las Regueras y barrios de la capital como San Claudio, San Lázaro, etc... en que la devastación ha sido absoluta".

${ }^{39}$ Según palabras del alcalde de Tarna, Benjamín Martínez, que le acompañaría en esta visita. AGA. Expediente 26/16452. Informe sobre el estado de reconstrucción de Tarna.

${ }^{40}$ M. BEASCOA, Op.cit., p. 5. 
El desarrollo de las obras en la localidad responde a un proceso muy dilatado en el tiempo y en el que participaron cuatro organismos diferentes: el Servicio Técnico de la Falange, la Excelentísima Diputación Provincial, la Dirección General de Regiones Devastadas y la Dirección General de Arquitectura. Esta sucesión de organismos provocó una reconstrucción poco efectiva, protagonizada por confusiones y malentendidos en relación a las obras materializadas, lo que dio lugar a un importante volumen de documentación cruzada que complica el seguimiento de los trabajos llevados a cabo.

Las dos primeras fases, realizadas por el Servicio Técnico de la Falange y la Diputación Provincial respectivamente (1938-1940), tuvieron como resultado la construcción, sin finalizar, de 33 viviendas que respondían únicamente a dos modelos (formados por: bajo con cuadra, cocina, baño y porche, y un piso con tenada, solana y tres dormitorios) determinados por la posición de su establo. Su presupuesto fue muy bajo debido a la intervención de Batallones de Trabajadores y, ante la dilatación de las obras, los tarninos se vieron obligados a solicitar su ocupación, pese a no estar culminadas.

El 25 de mayo de 1940, la Diputación cedió las obras a la Dirección General de Regiones Devastadas, actuando esta última como destajista y reintegrándole a la Diputación los fondos invertidos. En ese momento el escenario tarnino estaba conformado por 33 viviendas iniciadas y 37 sobre plano, de acuerdo al último proyecto de la Diputación Provincial. Este fue tomado como base para las posteriores reconstrucciones, pero revisado de acuerdo a dos aspectos: aumento de presupuesto y tipología de viviendas. El arquitecto Francisco de Saro proyectó hasta 8 tipos diferentes de casas, siempre en función de dos factores básicos: el número de miembros que componían la familia y, sobre todo, la actividad a la que se dedicaran sus inquilinos.
De entre ellas, cabe destacar el tipo " $\mathrm{D}$ ", que incluía entre sus dependencias un taller, ya que, además de la ganadería, otra de las actividades más importantes desarrolladas en el concejo era el trabajo de la madera, fundamentalmente el de la madreña ${ }^{41}$. A este respecto cabe señalar que, en contraposición a lo considerado para la vivienda urbana, la vivienda rural era concebida como un instrumento de trabajo, que incidía de manera determinante en la economía nacional $^{42}$.

Exteriormente, se promovía el mantenimiento de fachadas que conservaran el estilo rural del pueblo, un estilo regional -incluso pintoresco- que presentara una imagen de arquitectura tradicional al margen de que, interiormente, la distribución de los espacios y la preocupación por condiciones como la ventilación o la iluminación acercase, en gran manera, sus presupuestos a los del denostado Movimiento Moderno ${ }^{43}$.

Estas nuevas tipologías formaban parte del proyecto definitivo de urbanización de Tarna. Se trataba de un trazado fácilmente reconocible en el pueblo actual, lineal, en el que las viviendas adosadas en hileras daban lugar a calles anchas, rectas, que se cortaban en ángulo recto, facilitando el acceso al tráfico rodado. Como era habitual, todas las calles confluían en la iglesia, frente a la cual se urbanizó una pequeña plaza como lugar de reunión y de señalización del edificio en el tejido urbano (Fig. 2 y 3 ).

${ }^{41}$ AGA. Expediente 76/04/1191. Proyecto de once viviendas en Tarna. Francisco de Saro.

${ }^{42}$ L. PRIETO BANCES, "El proyecto y buen uso de la vivienda", Reconstrucción, n 17, 1941, p. 24. "La vivienda campesina ha de considerarse ante todo como un instrumento de trabajo, cuyo funcionamiento repercute en la economía agraria, que es bien común de la nación".

${ }^{43}$ Ibídem. "El aspecto externo de las edificaciones ha de contribuir a realzar el estilo local mantenido a través de muchas generaciones; unas veces para que el pueblo no pierda su carácter, y otras para desterrar el mal gusto que ha llevado al campo la imitación banal de lo que se hace en la ciudad". 


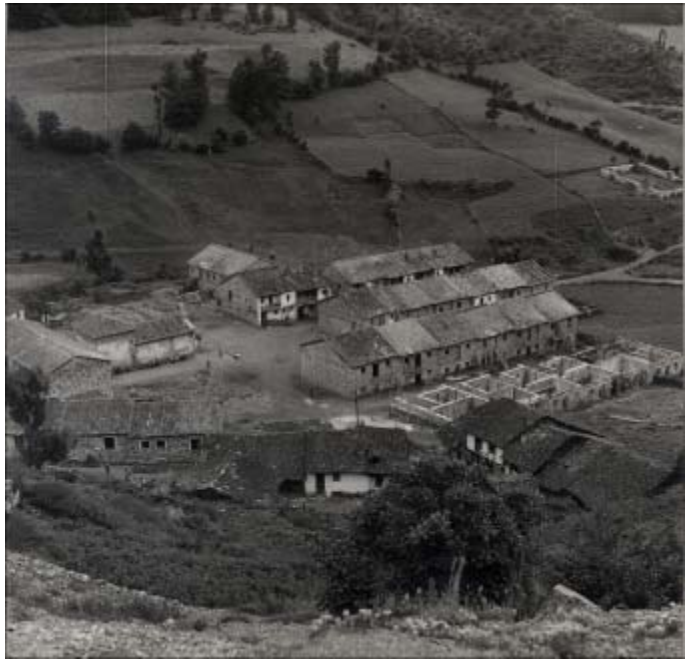

- Fig. 2. Proceso reconstructivo de Tarna en 1953. AGA, caja F-04228-026-004.

Sin embargo, no se registra obra alguna entre 1941 y julio de 1951. En 1950 se elevó a la comarcal de Oviedo un escrito reflejando, entre otros, el malestar de sus habitantes en relación a: los materiales y técnicas constructivas empleados -acababan de hundirse los tejados de las viviendas en proceso constructivo-, las dudosas expropiaciones llevadas a cabo en las que no se había llevado a cabo edificación alguna, la inadecuación de algunas de las obras y las consecuencias que las nevadas habían tenido en el pueblo por la falta de lugares de cobijo ${ }^{44}$. Este mismo escrito fue remitido al Director General del organismo, así como a otros tantos órganos competentes en el momento -como la Brigada Especial de Asuntos Sociales- al tiempo que en el año 1952 el propio Gobernador Civil se dirigía también al director de la Dirección General de Regiones Devastadas, exponiendo que Asturias estaba siendo relegada al abandono y que especialmente la reconstrucción de Tarna no iba a finalizarse nunca si no se ponía remedio ${ }^{45}$. Posteriormente, el alcalde rectificó este escrito, aunque lo cierto es que

${ }^{44}$ AGA. Expediente 76/13/20510. Escrito del alcalde de Tarna al director general de Regiones Devastadas.

${ }^{45}$ Archivo Histórico Provincial de Asturias. Expediente 24580/18. Correspondencia entre el Gobernador Civil y el Director General de Regiones Devastadas.

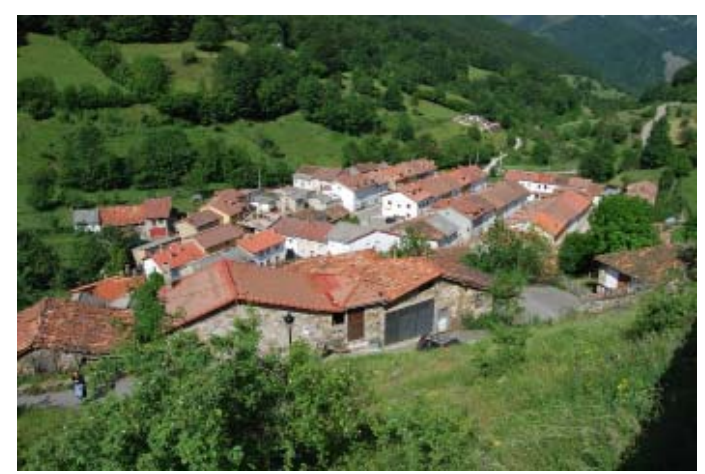

- Fig. 3. Estado actual y pueblo actual. Foto Luis Andrés.

la Brigada Especial de Asuntos Sociales, como organismo independiente, encontró evidencias de que estas reclamaciones eran una realidad.

En 1951 se reanudaron las obras en la localidad con la obligada instalación de la mano de obra procedente de Oviedo (a $80 \mathrm{~km}$.), considerada la medida económicamente más viable ${ }^{46}$. La mayor parte de las viviendas construidas se conservan en la actualidad con modificaciones propias del uso, como cerramientos, añadidos de pisos o intervenciones en su fachada, sin embargo, aún se pueden identificar fácilmente la mayoría de estos tipos. Del mismo modo, el trazado urbanístico sigue manteniéndose prácticamente sin cambios, ya que el pueblo no ha experimentado apenas crecimiento.

El conjunto ofrece al exterior la típica fachada-cerramiento de los pueblos reconstruidos por la Dirección General de Regiones Devastadas, que contribuyen a crear la idea de "pueblo cerrado". Se estudiaba el remate de la población de cara al campo, el alzado que iba a presentar el pueblo al entorno en el que estaba situado: usualmente se disponía una unidad

${ }^{46}$ AGA. Expediente 26/16453. Proyecto de diez barracones de madera provisionales. Francisco de Saro. 
completa de manzanas enfrentada con las calles circundantes de la población, cerrándola al situarse perpendicular a ellas, como podemos observar en el caso tarnino ${ }^{47}$ (Fig. $4)$.

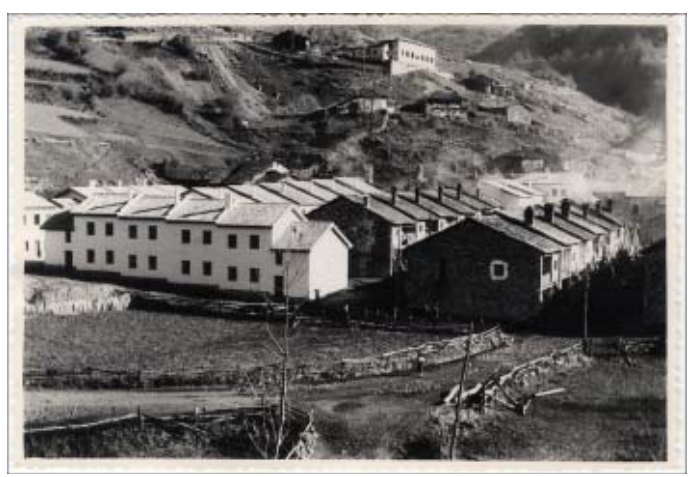

- Fig. 4. Fachada-cerramiento del pueblo de Tarna con las escuelas aún en lo alto. AGA, caja F-04228-26-003.

Para restablecer completamente los servicios básicos del pueblo, aún restaba solucionar algunos problemas urbanísticos y la intervención en dos edificios: la iglesia parroquial, que sufrió pequeños desperfectos al instalarse en ella el comedor del batallón de prisioneros y posteriormente el comedor infantil ${ }^{48} \mathrm{y}$ en la que se repararon cubiertas y pavimentos, y las escuelas. En lo referente a las escuelas, emplazadas en la parte alta del pueblo, habían sido utilizadas como cobijo de trabajadores y familias. El edificio no se recuperó, ante la aparente falta de interés de los organismos públicos, hasta que la Dirección General de Arquitectura, siguiendo el diseño del arquitecto Francisco de Saro para la Direc-

\footnotetext{
${ }^{47}$ M. BLANCO LAGE, "España una", en Arquitectura en Regiones Devastadas, Madrid, 1987, p. 19. Esta idea de pueblo cerrado era cierta, ya que para acceder a estas viviendas reconstruidas era necesario cumplir una serie de requisitos, según la circular 21, emitida en el año 1942: Ser vecino de la localidad antes del 18 de julio o haber sido destinados a la localidad en algún servicio del Estado, provincia o municipio. Carecer de vivienda propia, tener destruida su antigua vivienda, si era de su propiedad, o estar afectada por planes de urbanización.
}

${ }^{48}$ G. MARTÍNEZ TESTÓN, Op.cit., p.413. ción General de Regiones Devastadas, las reconstruyó sobre sus muros perimetrales en julio de $1957^{49}$. Las "escuelinas" no disfrutaron, sin embargo, de una larga vida y fueron derruidas, con la firme oposición de los tarninos, en el 2009. En su lugar, pese a la oposición generalizada, se ha instalado un edificio contemporáneo destinado a Centro de Interpretación del Urogallo, en desuso desde esta misma fecha de inauguración (Fig. 5). El sentir popular condena que, mientras en la época franquista se respetó el edificio precedente, ahora en democracia se haya tomado esta decisión de manera unilateral, instalando en su lugar una arquitectura completamente descontextualizada, de difícil comprensión en un entorno rural, y al que los habitantes apodan "el tanatorio".

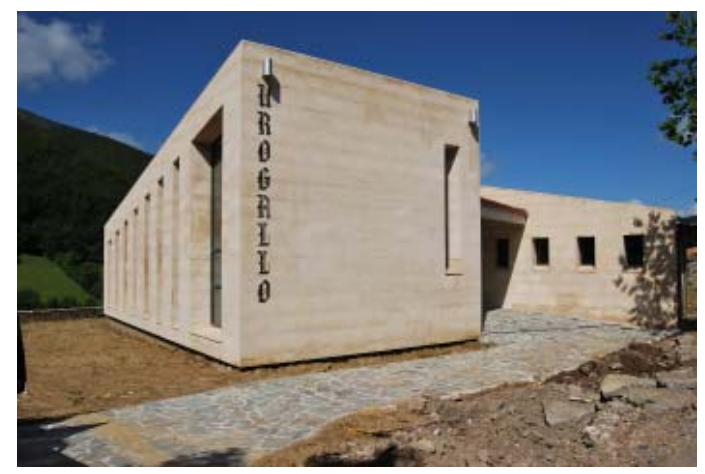

- Fig. 5. Actual edificio del Centro del Urogallo. Foto Luis Andrés.

Ya con la Dirección General de Regiones Devastadas extinguida y sin poder contar aún con aquel ideal de "pueblo adoptado" que se les había prometido en 1938, 23 años después los habitantes de Tarna se vieron obligados a volver a elevar un documento de queja, en esta ocasión dirigido directamente al general Franco, en el que, entre otras cosas, denunciaban que las viviendas aún no se habían culminado y que las cubiertas de algunas de las construidas habían vuelto a hundirse con las nevadas produci-

${ }^{49}$ AGA. Expediente 76/04/20510. Proyecto de reconstrucción de las escuelas unitarias para la localidad adoptada de Tarna. Francisco de Saro. 
das ese año, por lo que podemos dar por hecho que, efectivamente, la reconstrucción de este enclave tan importante en el imaginario propagandístico de la inmediata posguerra no se realizó con el rigor que hubiera merecido.

\section{NAVA: LA RECUPERACIÓN DE UNA IMAGEN}

El valor total de los daños ocasionados en Nava se elevó, según los datos manejados por la oficina técnica de la provincia, a 1,230.000 pesetas. Desaparecieron en la contienda un tercio de los 94 edificios de viviendas existentes en julio de 1936, presentando los restantes desperfectos por saqueo y bombardeos ${ }^{50}$. Pese a ello, únicamente hemos constatado un proyecto no materializado del organismo para un solo grupo de viviendas destinadas a maestros. Frente a esta tremenda carestía, los esfuerzos se centraron en los edificios representativos: la iglesia y su casa rectoral, el ayuntamiento, la plaza mayor y el cuartel de la Guardia Civil.

Aunque la adopción de Nava se produjo en 1941, su realidad no fue muy diferente a la de Tarna (en cuanto a las deficiencias de su materialización se refiere), de hecho 4 años después también el alcalde de la localidad se vio obligado a dirigir un escrito al director de Regiones Devastadas, reclamando que las obras aún no habían dado comienzo en el concejo. Esta situación no se solventaría hasta mediados del año $1946^{51}$.

Centrándonos ya en los edificios objeto de reconstrucción, hemos de señalar que la actual organización espacial de Nava, basada en su trazado medieval, se desarrolló en torno a La Plazuela, actual plaza mayor, siendo este el lugar en el que se centraron estas intervenciones. En ella

${ }^{50}$ AGA. Expediente 76/04/1184. Informe de daños.

${ }^{51}$ Archivo Municipal de Nava (en adelante AMN), Expediente 409 , orden n. ${ }^{\circ} 11$. Correspondencia entre la alcaldía y la Dirección General de Regiones Devastadas. serían objeto de reconstrucción: la iglesia parroquial, el ayuntamiento y la propia plaza (Fig. 6).

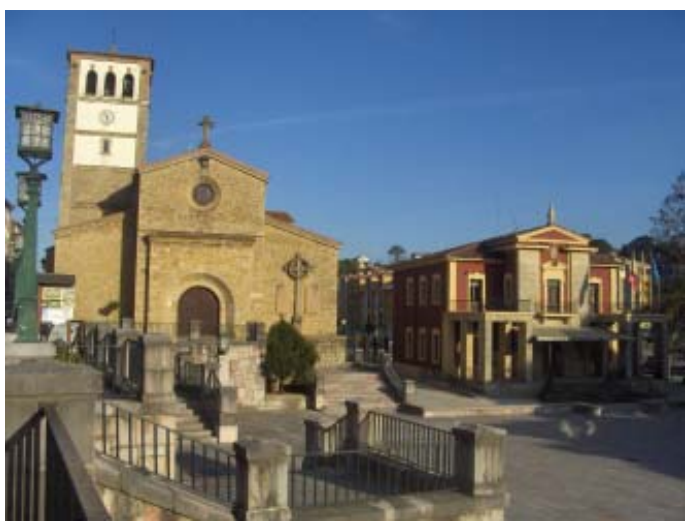

- Fig.6. La Plazuela con la iglesia de San Bartolomé y el ayuntamiento de Nava. Foto de la autora.

La iglesia de San Bartolomé aún se recuperaba de la destrucción y el saqueo del que había sido víctima en Octubre de 1934, cuando fue asolada por un terrible incendio que la dejó reducida a ruina. Posteriormente, el edificio fue demolido y sus piedras utilizadas como base de caminos, desapareciendo completamente la fábri$\mathrm{Ca}^{52}$. Su aspecto original lo conocemos a través de las escasas fotos conservadas y de las descripciones realizadas en el siglo pasado y primeras décadas del actual ${ }^{53}$. Se trataría de un templo probablemente de siglo XII, de notables dimensiones, nave única y arco triunfal al interior. Exteriormente, destacaría por su interés la portada polilobulada, de la que se conservan docu-

52 S. TORGA LLAMEDO, Evolución histórica del actual municipio de Nava, Oviedo, 1996, pp. 19-20.

${ }^{53}$ Basándose fundamentalmente en dichas fotografías y en las descripciones realizadas por José María Quadrado, Vigil Martínez, Manuel Fernández Ladreda y Aurelio del Llano, realizan una revisión de la iglesia:S. ÁLVAREZ MARTÍNEZ, El románico en Asturias, Gijón, 1999; M. FERNÁNDEZ PARRADO, Enciclopedia del románico en Asturias, Aguilar de Campoo, 2006, pp. 310314 y J. E. DÍAZ MAYOR, Biografía del concejo de Nava. Apuntes para la historia de una comarca asturiana, Buenos Aires, 1964, pp. 50-56. 
mentos gráficos e incluso una maqueta de escayola.

El párroco de la misma obtuvo a través de la esposa del Generalísimo el compromiso de financiación de su construcción ${ }^{54}$. Pese a que algunos estudios señalan a Luis Menéndez-Pidal como responsable de las obras, lo cierto es que la documentación conservada nos desmiente su autoría en el proyecto ${ }^{55}$. Consideramos que esta confusión podría deberse a su cargo de arquitecto jefe de la primera zona, que tendría entre sus funciones la de supervisar las intervenciones en la provincia asturiana. Se ocuparon de la obra de la nueva iglesia de Nava, por tanto, los arquitectos José Francisco Zuvillaga Zuvillaga y Juan Vallaure y Fernández Peña.

Se proyectó una iglesia de clara raíz historicista, neorrománica, que pretende evocar, al menos en sus líneas generales, a la destruida iglesia original. Esta recreación del edificio precedente, constante en la labor reconstructora de la Dirección General de Regiones Devastadas, tenía como objetivo recuperar la identificación que la memoria colectiva de los fieles mantenía con el templo primitivo, como en otras iglesias rurales de la región ${ }^{56}$.

Se proyectó la urbanización del terreno de la entrada de la iglesia en forma de escalinata proporcionando una peque-

${ }^{54}$ S. TORGA LLAMEDO, Notas sobre el municipio de Nava: sus gentes, historia y costumbres, Oviedo, 2008, pp. 345. El apoyo de Carmen Polo se materializó en su presencia, junto a la de su hija, en la inauguración de la iglesia en 1947.

${ }^{55}$ A ello añadimos la confirmación de nuestra hipótesis por parte del arquitecto Miguel Monedero, que había documentado la relación de intervenciones del arquitecto en la $1^{\mathrm{a}}$ Zona en su tesis doctoral. M. MONEDERO, Las restauraciones arquitectónicas de Luis Menéndez Pidal. La confianza en un método, Valladolid, 2008.

${ }^{56}$ M. ANDRÉS EGUIBURU, La reconstrucción de Gijón..., pp. 98-118. ña plataforma horizontal ante el atrio. Este elemento contribuye al efecto escenográfico de dominio de la iglesia, ligeramente elevada en un lateral de la plaza principal, sobre el resto de edificios de poder circundantes, de carácter civil. Esta escenografía se ve claramente reforzada por la construcción de una gran torre en el tramo primero de la nave lateral izquierda, erigida precisamente en dicho punto de la iglesia por ser más visible incluso desde la carretera y "hacer por lo tanto más eficaz su misión" que no es otra que subrayar la presencia de la Iglesia y de la reconstrucción llevada a cabo por el nuevo gobierno, consolidando al mismo tiempo ambos poderes. Las espadañas o campanarios de las iglesias se convirtieron en el hito principal de los pueblos, debido a la influencia que iban a tener en la imagen general de la población, haciéndola visible prácticamente desde cualquier lugar de la parroquia ${ }^{58}$ y contribuyendo con ello a elevarla como pieza reguladora de la vida en la misma. Otro elemento que resulta de gran interés es la utilización de los contrafuertes exteriores sin ninguna funcionalidad, descontextualizados, recuperando el arte prerrománico, arte de la monarquía asturiana y, por extensión, de la Reconquista.

Como recuerdo permanente del motivo que provocó los daños en la iglesia y de los acontecimientos acaecidos en la localidad, se colocó en la fachada principal de la iglesia un Monumento a la Memoria, recientemente retirado en aras de la Memoria Histórica. Este elemento, muy común en las obras de carácter religioso, contribuye a mostrar una reconstrucción con una intencionalidad propagandística e ideológica muy explícita (Fig. 7).

${ }^{57}$ AGA. Expediente 76/04/1184. Proyecto de la Iglesia parroquial de Nava. Francisco Zuvillaga

${ }^{58}$ M. BLANCO LAGE, Op.cit., pp. 29-30. 


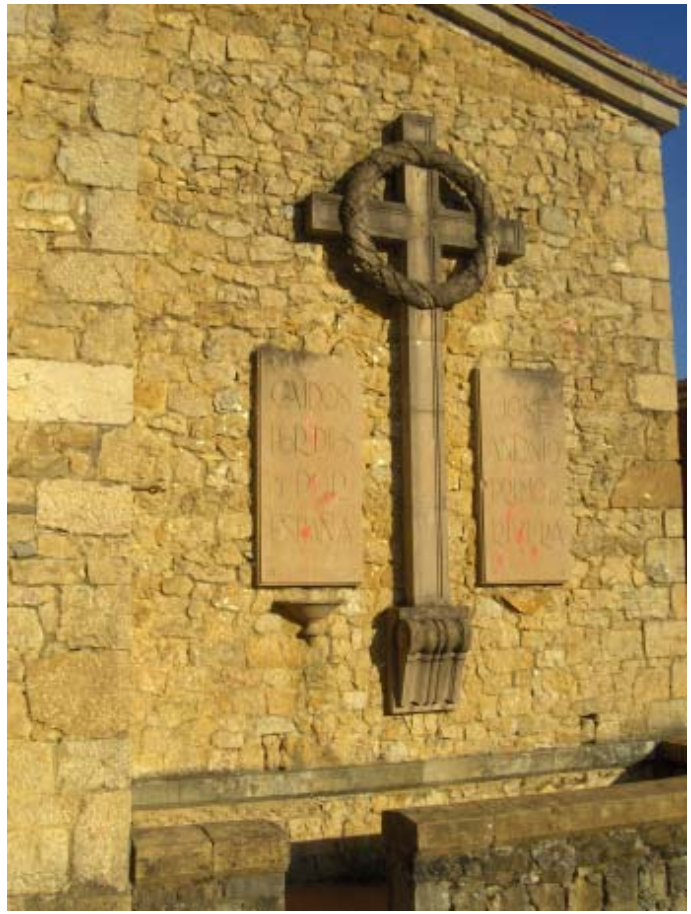

- Fig.7. Monumento a los Caídos en la iglesia de San Bartolomé de Nava. Foto de la autora.

En lo que concierne a la propia Plazuela, se presentaba como principal objetivo uno de los fundamentales en la tarea de Regiones Devastadas: recuperar la normalidad en la vida rural, evitando el citado éxodo rural. En este caso, dos eran las actividades que se desarrollaban en la plaza, además de la común de espacio de reunión: la celebración de los mercados semanales y las fiestas y bailes populares. La reconstrucción de espacios públicos de tal relevancia como éste suponían un punto clave en la afirmación del nuevo poder como reconstructor de un país "mutilado por los perdedores" y, a efecto, el propio Vallaure cita esta intencionalidad en una de las misivas enviadas al arquitecto Francisco Echenique reclamando la aprobación del proyecto ${ }^{59}$.

"Mi interés (...) como arquitecto de Regiones que ve la necesidad de que se le

${ }^{59}$ AGA. Expediente 76/04/4196. Correspondencia de la Dirección General de Regiones Devastadas. haga a ese pueblo tan destrozado por la guerra algo para todo el vecindario y que ha de mejorar notablemente su fisionomía; tanto que con poco dinero es obra que será de mucha propaganda para Regiones".

La Casa Rectoral y dependencias parroquiales se encuentran anexos a la iglesia. Exteriormente, el cuerpo superior se alza sobre dos pilares y presenta en esquinas y dinteles piedra vista, en una clara evocación a la arquitectura regional que, además, armonizaba con el estilo de la iglesia anexa. Interiormente, una de las mayores preocupaciones del arquitecto fue obtener luz natural y ventilación directa en cada una de las estancias, entroncando con los supuestos del denostado -y ocultado bajo estos fachadismos regionalistas o historicistas- Movimiento Moderno.

En cuanto al ayuntamiento, el edificio también había sufrido las consecuencias de la Revolución de 1934, en la que había sido incendiado, y se hallaba en proceso de reconstrucción en el momento en el que estalló la contienda. En un principio la Dirección General de Regiones Devastas asumió esta reconstrucción, pero posteriormente modificó con el objetivo de "dignificar" esta fachada, es decir, darle un estilo más imperial, ya que el proyecto no respondía a la reconstrucción representativa del nuevo poder que estamos desgranando ${ }^{60}$. Estas modificaciones añadían unas pinceladas de estilo escurialense, a través del almohadillado, los remates piramidales y las hornacinas abiertas en los macizos centrales. Además se añadió una teatral escalinata a la plaza que resaltara el edificio de poder civil y no desluciera junto a la imponente nueva parroquial (Fig. 8).

${ }^{60}$ AMN. Expediente 439, orden n. ${ }^{\circ}$ 3. Proyecto de reforma y terminación del edificio del Ayuntamiento de Nava. Juan Vallaure y Fernández Peña. 


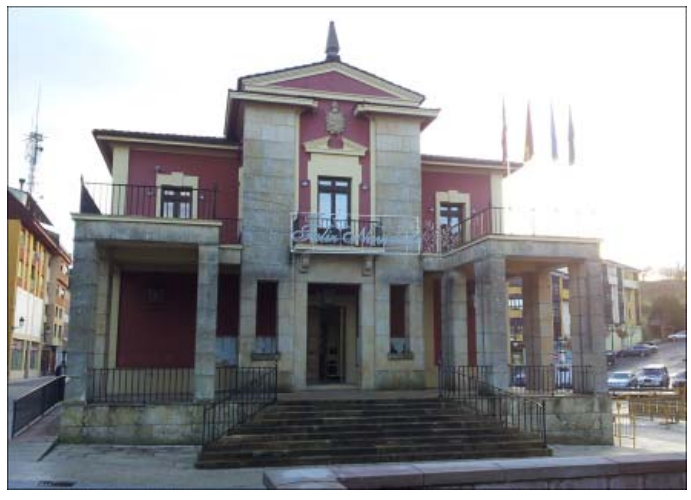

- Fig. 8. Casa consistorial de Nava. Foto de la autora.

Como última obra importante, aislado en una zona elevada del pueblo, se erige el cuartel de la Guardia Civil. Resuelto con gran sencillez y economía, presenta como única decoración la portada recercada con piedra y un alero del mismo material. Estos elementos realizados en piedra refuerzan la imagen de arquitectura de la montaña de la que se dotó a la provincia asturiana y estuvieron presen- tes, junto con grandes ménsulas de piedra y contrafuertes estrictamente formales, en gran parte de los edificios representativos intervenidos recuperando, de esta forma, modelos puramente regionalistas ${ }^{61}$. Además, nuevamente sus remates y almohadillado nos acercan al estilo escurialense, propio del revalorizado imperio español, que también analizábamos en el consistorio ${ }^{62}$ (Fig. 9).

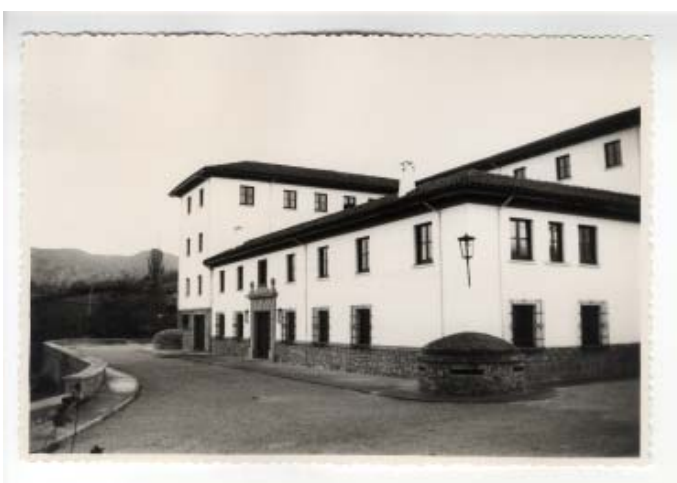

- Fig. 9. Casa cuartel de la Guardia Civil. AGA, caja F/04228-016-002.
${ }^{61}$ M. BLANCO LAGE, Op.cit., pp. 29-30.

${ }^{62}$ AGA. Expediente 76/04/1183. Memoria del Proyecto de Casa-cuartel para la localidad de Nava. Juan Antonio Miralles Sastre. 